\title{
STRUCTURAL ALIGNMENT IN CROSS-MODAL PRIMING: LINGUISTIC REPRESENTATION IS SHARED BETWEEN GESTURE AND SPEECH
}

\author{
JOLEANA SHURLEY ${ }^{1}$, MARIEKE SCHOUWSTRA ${ }^{2}$, and MARTIN J. PICKERING ${ }^{3} 3$ \\ ${ }^{1,2}$ Centre for Language Evolution, University of Edinburgh, UK \\ 11s1470688@ed.ac.uk,.2Marieke.Schouwstra@ed.ac.uk \\ ${ }^{3}$ Department of Psychology, University of Edinburgh, UK \\ martin.pickering@ed.ac.uk
}

There are robust findings that support a theory of interactive alignment, which indicate that communicative partners engage in various levels of synchrony during dialogue, both in the modality of speech as well as in gesture (Branigan et al., 2000; Schouwstra \& de Swart, 2014; Christiansen et al., 2016). Interactive alignment is largely a consequence of priming (Pickering \& Garrod, 2004). Recently it has been found that priming plays a role in artificial language change towards maximally regular and highly predictable linguistic systems (Feher et al., 2016), and in the emergence of linguistic conventions in silent gesture studies (Schouwstra et al., 2016). Silent gesture experiments, which use hearing participants, indicate that an individual's choice of constituent order (e.g., SOV) is primed by their communicative partner's own syntax. To further investigate the potential role of priming, we introduce a novel paradigm to investigate the extent of interactive alignment within cross-modal communication, from gesture string comprehension to verbal speech production.

We used a picture-matching game to test structural alignment between the syntax used in gesture strings and the word order produced in speech. A confederate to the study gestured events depicted in a set of pictures (see Figure 1), and the participant chose the correct card out of an array presented on-screen. Subsequently, the participant verbally described their own set of target cards to the gesturer. Crucially, the gesturer followed a script that systematically varied in the syntactic structure of the dative alternation (depicting PO, prepositional-object, or DO, double-object sentences) when manually describing the set of cards. Participants were led to believe they were interacting with the gesturer by sending recordings via a network connection. In fact, the participants were viewing pre-recorded videos of gestures.

Figure 1: Experimental item drawn from the gesturer's description set of virtual cards, corresponding to the double-object dative sentence: "[A/The] boxer shows $[\mathrm{a} /$ the $]$ ballerina $[\mathrm{a} /$ the $]$ book."

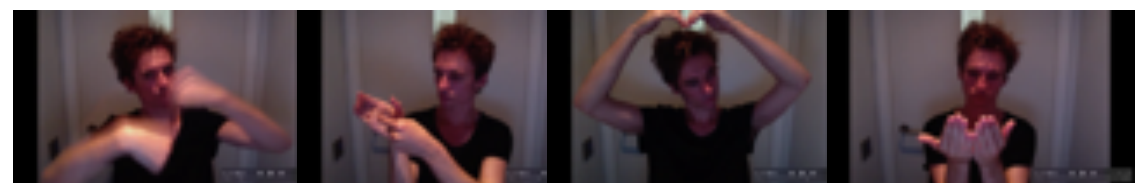


The verbal descriptions gathered from the participant served as the target responses used in analysis. Table 1 reports the proportion of target responses in the different conditions. Half the participants described cards that were the same as those actions depicted in the prime ('throw', 'sell', 'show', 'give'), and the other half described cards that were mismatched, or different. We investigated whether using the same lexical item and a similar syntax provided a 'lexical boost', whereby participants produced more linguistically aligned target responses than if they were primed by similar syntax alone (Branigan et al, 2000). To obscure the nature of the study, as well as priming methods, these items were interspersed with filler items, which depicted simple transitive sentences (where only one direct object is obligatory).

\begin{tabular}{llll}
$\begin{array}{l}\text { Table 1: Percentage of target responses in each of the four conditions } \\
\text { Verb type }\end{array}$ & Prime Description & $\begin{array}{l}\text { Target } \\
\text { description }\end{array}$ & \\
\cline { 2 - 4 } & & PO & DO \\
\hline Same & PO & 0.92 & 0.08 \\
& DO & 0.79 & 0.21 \\
Different & PO & 0.95 & 0.05 \\
& DO & 0.86 & 0.14 \\
\hline
\end{tabular}

PO: prepositional-object; DO: double-object

We ran a linear mixed effects model looking at the proportion of DO produced, entering prime order and sameness of verb as fixed effects and participant and verb target as random effects. Overall, participants had a preference for PO over DO, which is reflected in the intercept (beta $=-2.07, \mathrm{SE}=.39, \mathrm{p}<.001$ ). In trials following a DO prime, they were significantly more likely to produce DO (beta $=0.915, \mathrm{SE}=.41, \mathrm{p}<.05$ ). No interaction was observed between prime order and sameness of verb (beta $=0.151, \mathrm{SE}=.55, \mathrm{p}=.78$ ).

Our results illustrate that structural properties of silent gesture influence the syntactic structure of verbal descriptions, i.e. showing evidence of cross-modal priming. This is interesting because silent gesture, when used in production, has been shown to by-pass native language rules (Goldin-Meadow et al., 2008), and can be seen as the result of an improvisation process, reflecting cognitive biases of the gesturer (Schouwstra \& de Swart, 2014). The fact that spoken English can be primed by this mode of communication shows the far-reaching effect of silent gesture, and its potential role in emerging language situations (Kelly et al., 2008). This interpretation is strengthened by the fact that no lexical boost effect was observed in this experiment: participants did not simply 'translate' the gesture strings into their native language. 


\section{References}

Branigan, H. P., Pickering, M. J., \& Cleland, A. A. (2000). Syntactic co-ordination in dialogue. Cognition, 75(2), B13-B25.

Fehér, O., Wonnacott, E., \& Smith, K. (2016). Structural priming in artificial languages and the regularisation of unpredictable variation. Journal of Memory and Language, 91, 158-180.

Goldin-Meadow, S., So, W. C., Özyürek, A., \& Mylander, C. (2008). The natural order of events: How speakers of different languages represent events nonverbally. Proceedings of the National Academy of Sciences, 105(27), 9163-9168.

Kelly, S., Manning, S., Rodak, S. (2008). Gesture gives a hand to language and learning: Perspectives from cognitive neuroscience, developmental psychology and education. Language and Linguistics Compass, 2(4), 569-588.

Pickering, M. J., \& Garrod, S. (2004). Toward a mechanistic psychology of dialogue. Behavioral and brain sciences, 27(2), 169-190.

Schouwstra, M., Smith, K., \& Kirby, S. (2016, March). From natural order to convention in silent gesture. In The Evolution of Language: Proceedings of the 11th International Conference (EVOLANG XI). EVOLANG XI, New Orleans, United States 20, 24.

Schouwstra, M., \& de Swart, H. (2014). The semantic origins of word order. Cognition, 131(3), 431-436.

Christensen, P., Fusaroli, R., \& Tylén, K. (2016). Environmental constraints shaping constituent order in emerging communication systems: Structural iconicity, interactive alignment and conventionalization. Cognition, 146, 67-80. 